\title{
Rational Thought on College Teaching Management Reform Based on Quality Awareness
}

\author{
Xiaoping Wang, Naizhu Huang (Corresponding author) ${ }^{*}$, Jiaming Zhong \\ Xiannan University, Hunan, Chenzhou, 423000 \\ huangnzh@163.com
}

Keywords: Quality awareness; College; Teaching management; Reform

\begin{abstract}
To boost education quality is a core goal of college teaching management. College teaching management reform is closely related to college-running idea. The core contents of college teaching management reform include the following: reshaping college spirit, optimizing college-running philosophy, reforming teaching management system, and constructing chaotic organization of college teaching management, free teaching objective, complete credit system and curriculum system paying attention to foundation and respecting selection. To enhance education quality is the lifeline and eternal theme of colleges. British educator Peter Scott considers in the popularization process and after popularization, with quantity expansion, education quality is very crucial for development of higher education and also a topic that all sectors of society pay close attention to[1]. As popularization of higher education arrives in China, colleges continuously increase enrollment, which results in many problems, such as large differences in the quality of student pool and shortage of student resources. Hence, severe challenges are brought to college teaching management, teaching reform and sustainable development of colleges. In order to adapt needs of situation development, colleges must establish scientific education development view, stick to stabilization of scale, optimization of structure, consolidation of characteristics and attention to innovation and walk the way of connotative development cored by quality promotion. Connotative development must highlight central position of teaching, reform teaching management idea and system, stimulate teachers and students to work on teaching research, strive to boost education quality and promote sustainable development of colleges.
\end{abstract}

\section{Quality and education quality}

In natural science field, mass usually refers to physical quantity to measure inertia of objects. With social development, quality concept is continuously enriched and deepened continuously. In management field, quality is usually regarded as product quality, i.e. the degree of meeting users' demand during using the products. Beyond all doubt, product quality is the lifeline of an enterprise. Similarly, education quality is also the lifeline of an educational institution and also the supporting point of educational reform and development of colleges.

Education quality is the objective of educational activities. The educational activities without quality significance are worthless. Due to complexity and diversity of educational activities, there is no recognized concept of education quality. Different people and different institutions have their specific connotation and denotation during studying education problems. The view of education

Corresponding author 
quality is people's education value choice under specific conditions. It involves the relationship between social development and human development, the relationship between scientific education and humanistic education and the relationship among education law, scientific development logic and social development. Education is an activity which aims to facilitate social development and human development. Its value must be established on the basis of these two purposes. In accordance with such view of education quality, we consider education quality of colleges is the degree of students cultivated by, knowledge created and services provided by higher educational institutions meeting current and future social needs and students' individuality development need on the basis of following education law and scientific development logic and under established social conditions. In higher education activities, education law and scientific development logic restrict realization degree of higher education quality. Such restriction is an internal factor of pursuing two needs by higher education, so it must be respected and treated seriously. Moreover, established social conditions define two needs. In other words, social development need and students' individuality development need alter with the development of times. The view of education quality always adapts social environment and educational environment when the measurement standard is established so that the view of education quality is correlated to specific social conditions and has specific contents and standards. Hence, the contents of view of education quality must be correspondingly adjusted with social changes so as to make higher education activity develop towards the direction people expect and better meet social development need and human development need. In educational practice of colleges, education quality standard diversification must be made clear in order to develop connotation of education quality scientifically, because higher education quality is a concept involving multiple levels...In view of diversity and to avoid measurement with a uniform measure, multiple levels include junior college, four-year university, master and doctor as well as skill, application, theory and research. Various colleges do not need blindly seek common ground and progress. Junior colleges pursue four-year universities. Four-year universities pursue to become the key universities. Key universities are devoted to edge themselves into world-class universities. In this aspect, American multi-level and multi-category higher education system can serve as reference. Carnegie Classifications of Higher Educational Institutions revised in 2000 classifies colleges into two categories. Different types of colleges have different orientations and school-running characteristics. Low level does not mean low education quality.

\section{Reform of college teaching management philosophy}

To enhance education quality, colleges must make talent training mode innovative and reform teaching management philosophy. Teaching management philosophy is decided by school-running philosophy. Thus, college running philosophy must be first optimized.

Optimization of college running philosophy. Present college running philosophy is administration-dominated in China. Colleges lack autonomy in running schools. The Central Committee of the Communist Party of China and the State Council issued Guiding idea about boosting reform of public institutions by classification in April 2012. The idea mentions public institutions which provide public services for society, active exploration of effective realization form of government regulation separating from management and gradual cancellation of administrative level, but there is still a long way for de-administration of colleges. Many scholars are amazed that National Academy in ancient times also stressed morality and integrity under harsh governance of feudal imperial power; in modern times, Cai Yuanpei from Peking University initiated democratic 
atmosphere of "academic freedom and all-inclusiveness"; Chen Yinke from Tsinghua University advocated "independent personality and free thought". Why do moral decline, spiritual collapse and academic foam occur frequently? Administration of college running philosophy results in the loss of college spirit, which is the root cause. To reshape college spirit, it is necessary to surpass humanistic spirit and universal value of money and status. Hence, it is more valuable to review Cai Yuanpei's college running philosophy at the beginning of the 20th century.

Cai Yuanpei considered that colleges should have multiple functions such as personnel training, knowledge communication, academic research and education of society[2]. Colleges regard academic research as the main idea: colleges are not the places for fixed knowledge infusion, but the institutions studying knowledge. Kant said, "college is an academic community. Its moral character is to independently pursue truth and academic freedom"; colleges should regard guiding the society and serving the society as the mission; colleges should guide society to pursue freedom, equality, democracy and scientific spirit. At all times and in all over the world, the reason why colleges are called the tower of ivory is that colleges are the forerunner of whole social thought and the source of dreams. As social model and cultural center, colleges should take the lead to construct social morality, correct vulgarity and cultivate morality, shoulder the responsibility of cultivating social morality. Colleges should provide knowledge services for all walks of life and cultivate college students to honest workers serving the society. College education aims to educate people rather than manufacture devices: education is to help the people to be educated and to provide them with the ability to develop themselves and complete their personality, instead of training the people to be educated to special tools. Einstein said, college was not just knowledge impartation place and vocational cultivation place, and its fundamental task and function was to cultivate harmonious persons; such persons owned knowledge, technology and basic humanistic feelings. Humanistic feelings mean to care about human spiritual problems and pay attention to one's and other's spiritual growth. To be more specific, it is necessary to ponder over and explore the aim of life and the relationship among people, the relationship between human and society, the relationship between human and nature as well as the relationship between human and universe, establish spiritual belief through thinking these problems, and lay a solid foundation for one's life. Meanwhile, it is necessary to continuously exploit spiritual free space, mould one's temperament and character, enrich and develop individuality in development of personal interests and hobbies, improve spiritual state, dig and develop imagination, aesthetic sense, thinking ability and creativity. College education takes innovation as the soul. Innovation is intellectual impetus for a nation to never stop. Cai Yuanpei's innovation performance is the example. He regarded reform idea as the guidance and deemed management system reform as the guarantee to actively promote discipline construction, teaching team construction and curricula construction. Innovation idea means colleges should abandon narrow family idea and carry out the college running policy of freedom of thought and all-inclusiveness; teachers should get rid of emotion and desire of officialdom, establish the thought of devoting themselves into teaching; students should discard obsolete awareness of imperial examinations and establish the thought of regarding academic research as their bounden duty; management system reform advocates university management by professors, democratic decision-making and responsibility for college affairs by division of labor; in teaching team construction, based on the principle of all-inclusiveness, new school figures should be introduced in quantity and attract talents. At one time, famous teachers gathered in Peking University; both new and old schools discussed academics together; this was the period of academic prosperity; in terms of school system reform and 
curricula construction, curricula selection system is carried out on the basis of free education view advocating nature and displaying individuality; based on the principle of sharing both Chinese and western elements and selecting the advantages, the curriculum system is established.

Transformation of college teaching management philosophy. Transformation of college teaching management philosophy is guided by college running philosophy. Its aim is to construct chaotic environment contributing to free development of college students. Chaos is a concept in physics. It refers to the state of things between order and disorder. Chaotic environment of teaching management means that teaching management should create certain uncertainty so as to promote teaching to generate plentiful knowledge and innovation and facilitate vivid and lively development of college students. When any systems are at the edge of chaos between too many organizational frameworks and no any organizational framework, they may self-combine to generate complex adaptation behaviors. If there are too many organizational frameworks, the system will generate cultural atmosphere of keeping on the rails, rigid processing program and too narrow communication channels. As a result, the loss of flexibility, immature reform and wrong products will occur. If there is short of organizational framework, the system will speed up to destroy rules, and then organizational loose relationship or chaos caused by random exchange will happen. Meanwhile, the expected objective ad service cannot be realized. For college teachers and college students, if a college formulates too many teaching rules and regulations, both teachers and students have no freedom. Teachers' teaching will not own characteristics, and it is hard for students to become innovative talents. Brown and Eisenhart proposed organizational environment at the edge of chaos: under few rigorous rules, support a frequently-changing culture; based on confirming activity emphasis, effective measures, real deadline and responsibilities, create loose structure for the activity as far as possible; create fact-based exchange between the internal and organization[3]. Of course, teaching at the edge of chaos does not mean to accept government-free stage. Really chaotic teaching has no clear direction; rights and obligations are unclear; exchange is full of randomness. It is very difficult to reach knowledge innovation in such learning environment. By contrast, the edge of chaos contains order and openness. The factors consisting of order include explicit morality objective, clear problems to be solved and absorption of knowledge and information from problem solving results and evaluation results. Since teaching is at the edge of chaos of order and openness, a lot of interactions and creative collisions are generated between teachers and students and among students. Hence, knowledge innovation related to problems surge continuously. At the same time, all kinds of conflicts and diversification emerge. As long as teachers require college students to mutually respect conflicting parties, such conflicts under complex and turbulent conditions may be evolved into creative breakthroughs. The result of consistent views in an organization is expected by all, but this cannot be achieved in fact unless a consensus is reached. Human creation process is bound to numerous, complicated and disorderly, full of differences, conflicts, fantasies and impulse. In teaching process, we should sufficiently respect diversity and keep tolerant attitude to those strange and dissocial college stud nets who challenge rules. Excellent college presents lay emphasis on their views, hobbies, individuality, values and skills during choosing teachers, because diversified culture is heterogeneous culture. Conflicts hide in heterogeneous culture which also contains breakthrough seed. As long as we learn from each other based on the principle of respect, we can creatively develop. 


\section{Reform of college teaching management system}

Advocate teaching manage ment system of free teaching. College teaching management is based on control principle of planned economy. Freedom right of teachers and students in teaching is small, but the control is very strong. In Greek, the meaning of school is leisure. Students must have abundant time to experience and ruminate in order to freely develop their mentality and ability. Jaspers said that, the basic mission of college education lied in enlightening human free nature through culture edification. Einstein recalled his studying experience and said, "After entering school, he found he did not own all characteristics a 'good' student should have, such as being absorbed in lessons, abiding by classroom discipline and doing assignments. Thus, he was always a student with medium academic performance and put his main energy in those he was interested in and learned from masters in theoretical physics with great passion... Then, he recalled that, after grading from university, what made he feel happy was that he landed a practical job in the Patent Office, rather than doing researches in the university, because campus life would put a young person in such passive position: he had to write large quantities of scientific papers - as a result, he would tend to superficiality". Einstein's successful experience is not a particular case at all. Regardless of the field of science or the fields of philosophy, literature and art, almost all geniuses were not "good students" in school and had the experience in struggling against educational system at that time. It can be said that their history of becoming talents is the freedom history of getting rid of school education constraints and striving for autonomous study. The philosopher Zhou Guoping said that, "modern institutionalized education deeply poisons teenagers. All excellent students need to keep vigilant for damages caused by institutionalized education. He considers learning effect of a student depends on his freedom of independent study he strives for in the face of institutionalized education"[4]. College teaching management aims to cultivate students" awareness of "free reading and free thinking". Free learning owns the following meanings. Firstly, they should intensively read Chinese and western classics where the essence of Chinese nation and human civilization gathers. Students should read them carefully over and over again and do not need to read too many books; secondly, students should extensively read as far as possible. As Lu Xun said, students should especially reach the books beyond their specialties and like reading without requiring understanding; after reading a lot, they would naturally comprehend by analogy. Except free reading, free thinking is also important. Students should neither have preconceived idea nor have superstition for any authority, but should innovate, keep independence, propose "why" and "doubt" and write down their own thinking, experience and questions anytime. If they persist in this way and accumulate over a long period, they will certainly have harvest. Based on extensive reading, students will certainly find out the masters who have the same views with you. Then, they should concentrate to real all of the masters' works and do special researches as their spiritual pillar. The experience of a scholar studying in America brings enlightenment[5]: this student was once the winner of gold award in World Olympic Physics Competition; after his graduation from senior high school, he was recommended to Peking University without any examination; now he is studying at MIT; in his opinion, he basically spent university life in chaos in China; one can choose 10 or more courses in one semester, as long as he finally passes the examinations. Although he just chooses 5 courses at MIT, he feels very busy. Teacher of every course requires students to read extensively. For some courses, a lot of experiments are required. If he teats them lightly, he may be unable to keep pace with other students. At night, he stays up late to read in the library frequently. It's no wonder that foreigners point out when evaluating Chinese college students that, the scope of knowledge is narrow; especially, there is lack the accomplishment in music, painting, sports and art which influence one's living quality; college 
students lack the time and space which can be dominated by them freely; they fail to cultivate their consciousness of innovation and ability; their specialized knowledge is good, but their tacit knowledge such as curiosity, thirst for knowledge, self-confidence, positive emotional experience and social sense of responsibility is insufficient obviously. These are exactly the spirit, soul and driving force supporting a person. Current colleges cram knowledge in students' brain and ignore the ability to learn knowledge independently. This undoubtedly hinders students from leading to the spirit of freedom. Non-systematic specialty and knowledge as well as impartation of examination skills weaken original spiritual life, students' reflective ability, independent individuality and the habit of pondering over a question repeatedly[6]. College education should let students choose freely. The teaching plan and program just aim to help students to attend class, and should not limit students' free of attending class. Free teaching and learning of college teachers and students need to cultivate library awareness, because whether one can take full advantage of library can serves as an important standard to judge whether this person can carry out inquiry-based learning and innovate in the future. The philosopher Zhou Guoping pointed out that, "bookshelves in the world are filled with spiritual delicious food, but college students are forced to read dull textbooks without any nutrition."[7] Whether college students in the times of information can achieve success depends on their ability to discover, gain, analyze and summarize information and knowledge as well as combine information, knowledge, individuals and career life.

Advocate teaching manage ment system of complete credit system. The implementation of college free teaching objective needs complete credit system as the guarantee. At present, credit system is just a teaching management form based on controlling thinking. Education should make sure everyone enjoys the freedom in thought, judgment, emotion and imagination in order to give full play to their talents and firmly master their fate.[8] However, the reality is opposite. Chinese and western differences in talent training philosophy are as follows: western countries pay attention to growth, deem quality as the basis, follow the law of nature and comply with students' interest, will, selection and natural growth and are free from external disturbance; the source of Chinese talent training philosophy is shaping. Shaping means that the educatees as the raw materials are put in standard mould ad production line, and the products produced are standard products. Thus, students have no individuality or creativity. This is the feature of Chinese school education. Credit system teaching management is an inevitable choice of Chinese higher education reform and development. From academic year system, credit system to complete credit system, it reflects changes of educational concept and is also the result of educational system reform. Existing credit system in China is not real flexible system. It is very hard for students to complete the credits in advance. Even if they complete the credits in advance, it is very difficult for them to graduate ahead of time. Hence, the effect and function of credit system are greatly affected. Because of elimination system, colleges almost become "safe boxes". As long as students enter colleges, they can gain credits and diploma without the need of studying assiduously and carefully. Serious shortage of during force for learning becomes a universal phenomenon. Complete credit system originating from Harvard University in the 19th century is a kind of teaching management system under which students can graduate as long as they complete the total credits required. It requires the credit of each course is confirmed according to credit hours of each course as per cultivating objective and teaching program. Required courses and optional courses are set. The proportion of various courses and the minimum credits for graduation are stipulated. There are two features for complete credit system: teaching management is more flexible and complex, and management by objectives and individuation of teaching and 
learning are stressed; talent training diversity and learning time flexibility. To implement complete credit system, firstly, it is necessary to construct rational course system. Planning of professional courses should be emphasized. Meanwhile, flexibility of courses related to other specialties should be reflected so that students own solid and rich knowled ge reserve and can mainly grasp professional knowledge and skills in order to meet social demand for inter-disciplinary talents. Secondly, adequate course teaching resource and flexible course selection system also need. In other words, students choose courses according to teaching plan, teaching requirements, their intelligence and physical conditions. Hence, colleges should optimize course structure, open high-quality and sufficient optional courses, and provide crossed courses, serious courses or module courses for students. At the same time, cross-college course selection and credit admission should be positively promoted. Finally, students and especially freshmen should be organized and guided for course selection to avoid blindness and randomness. Under complete credit system, tutorial system may be introduced for course selection, in charge of advertising functions, contents and requirements of credit system and other teaching management systems, guiding students to formulate personal development plan, guiding and organizing students to select courses, rationally calculate credits and GPA according to teaching plan and select courses in combination of personal strong points and hobbies, and urging students to complete the required credits so as to better promote perfection of coursed section system.

Advocate course management system which focuses on foundation and respects choice. Complete credit system needs profound reform of college education mode. At present, there are two typical education modes in the world: liberal education and professional education. Chinese colleges still adopt professional education mode. The disadvantages are as follows: specialty division is too detailed; students' scope of knowledge is too narrow; it is hard to cultivate outstanding talents. On July 29, 2006, when Premier Wen Jiabao paid a visit to Mr. Qian Xuesen, Mr. Qian proposed a very significant suggestion on education: no college in China is operated as per the mode to cultivate innovation talents, which is a serious problem. Mr. Qian Mu - master of Chinese culture in Taiwan become a talent by self-study. He considered college education should abandon professional education mode and advocate liberal education mode, because the highest state of education is to let students develop freely, be themselves and construct the best platform for their wonderful life through personality shaping, inheritance of wisdom and good merits such as freedom, justice, hope and love. College teaching management reform should adjust course plan according to liberal education mode, gradually reduce credit requirement for graduation, cut down the proportion of required courses and increase students' independent learning and selection space. Meanwhile, it is necessary to course quality construction, perfect course system, form high-quality course series represented by main elementary courses, general courses and platform courses. Main elementary courses are a batch of courses which play the foundation and supporting role for talent training and disciplinary development. These courses are accumulated in the history of college running. Various colleges should adopt a series of measures to enhance construction of main elementary courses. For example, famous teachers, well-known scholars and professors teach main elementary courses in order to ensure teaching quality of main elementary courses. In quality-oriented education, general courses aim to meet needs of quality-oriented education. General courses must be examined and approved by the committee of experts of colleges, including mathematics \& natural science, social sciences, philosophy \& psychology, history \& culture, linguistics, literature and art, education and social sustainable development etc. Besides, some Chinese and foreign classical courses may be 
provided, such as intensive reading of The Four Books, western thought classics and reading of Chinese and foreign classics. The opening of platform courses is based on discipline fusion and cross. This trend becomes increasingly obvious. Colleges may provide science and engineering, humanity, social sciences and operation \& management courses for students. This is an important move for cultivating innovation ability of college students.

\section{Acknowledgement}

The result of this research is subsidized by the key topic of Ministry of Education in 2009 in "the 11th Five-year Plan" of nationwide education science - Study on evaluation of job performance of local college teachers (DFA090237).

\section{References}

[1] Anthony Smith and Frank Webster, The Postmodern University--Contest Visions of Higher Education in Society, Buckinggham , Open University Press, 1997.

[2] University view of Cai Yuanpei [EB/OL], May 29, 2012, Sohu Education

[3]Brown, S. and Eisenhardt, K. (1998) Competing on the Edge, Boston, MA, Harvard Business School Press, p.47.

[4] Zhou Guoping, Zhou Guoping's discussion about education [M]. East China Normal University Press, 2009, 254.

[5] Zhu Qingshi, corruption phenomenon in society could be found in colleges [N]. China Youth News, May 3, 2012

[6]Jaspers, What is education? [M]. Translated by Zou Jin. Beijing: Sanlian Bookstore, 1991, 33

[7] Zhou Guoping, Zhou Guoping's discussion about education [M]. East China Normal University Press, 2009, 6.

[8]UNESCO International Education Development Committee, Education - wealth hidden in it [R]. Translated by Chinese Department of UNESCO headquarters. Beijing: Science and Education Press, 1996, 78.

[9] Hammer M,Champy J. Reengineering the Corporation: A Manifest for Business Revolution [M]. New York, Harper business, 1993.

[10] Jinzhong Li, The new trend of American teacher evaluation [J]America teacher evaluation, 2004, (3):10-13. 